\title{
A cross sectional knowledge attitude practice study on therapeutic drug monitoring among health care professionals in a tertiary care hospital
}

\author{
Poovizhi Bharathi Rajaduraivelpandian*, Padmaja Udaykumar
}

Department of Pharmacology, Father Muller Medical College, Mangalore, Karnataka, India

\author{
Received: 10 February 2020 \\ Revised: 01 May 2020 \\ Accepted: 06 May 2020 \\ *Correspondence: \\ Dr. Poovizhi Bharathi Rajaduraivelpandian, \\ Email: poovizhi.bharathi@gmail.com
}

Copyright: $@$ the author(s), publisher and licensee Medip Academy. This is an open-access article distributed under the terms of the Creative Commons Attribution Non-Commercial License, which permits unrestricted non-commercial use, distribution, and reproduction in any medium, provided the original work is properly cited.

\begin{abstract}
Background: Therapeutic drug monitoring (TDM) is used to optimize drug's therapeutic effect. Aim of this study is to assess the knowledge, attitude and practice of TDM in health care professionals.

Methods: This was a questionnaire-based cross-sectional study. Questionnaires were distributed to 610 nursing staff and 20 lab technicians. Questionnaires had queries on demography, knowledge, attitude and practice. Descriptive statistics and Pearson correlation were used to analyse the data.

Results: Among nurses, 7\% had good, $60.9 \%$ had fair and 32.2\% had poor knowledge of TDM. Among lab technicians $18.2 \%$ had good and $81.8 \%$ had fair knowledge on TDM. $79.3 \%$ of nurses and all lab technicians had favourable attitude towards TDM. Weak positive correlation is seen between knowledge and attitude among nurses. $15.9 \%$ of nurses have sent request for TDM on phenytoin, sodium valproate, carbamazepine, methotrexate, lithium, clozapine, risperidone, tigecycline, vancomycin, gentamicin, digoxin and amiodarone. 100\% lab technicians have estimated levels of methotrexate and lithium drug sample during the last one year.

Conclusions: Though knowledge on indication and pharmacological basis of TDM is lacking among participants, their knowledge on sample collection and sample type is good. They have a positive attitude towards TDM. Nurses have requested TDM for only 12 drugs. TDM of only two drugs was done by lab technicians. Future training should focus on pharmacological basis, selection of appropriate drug candidate and indication for TDM service. TDM service should be made available in all tertiary care institutions.
\end{abstract}

Keywords: Adverse drug reaction, Cost benefit ratio, Lab technicians, Nurses, Therapeutic index

\section{INTRODUCTION}

Precision medicine for patient management is achieved by many tools including Therapeutic drug monitoring (TDM). ${ }^{1}$ Medication dosage for an individual is tailored based on characteristic of the patient, properties of drug and drug concentration in blood. TDM is essential in pharmacotherapy of neuropsychiatry patients because of wide interindividual variation in pharmacokinetics. The variation is augmented by extremes of age, coexistent disease, concomitant medication and genetic defect.
TDM is required when a particular drug therapy is substituted from one pharmaceutical preparation to other, as it modifies the absorption pattern and consequently the drug concentration. By quantifying concentration of drug in patient's blood serum or plasma, TDM guides to titrate drug dosage in an individual to provide the highest drug efficacy with the lowest risk for adverse drug reaction. ${ }^{2}$

In the last four decades in oncology therapy, TDM for 5fluorouracil has a validated algorithm for dose alteration. ${ }^{3}$ TDM is feasible and safe in several Kinase inhibitors 
such as imatinib, sunitinib, pazopanib, everolimus, and tamoxifen. ${ }^{4}$ Individual exposure of carboplatin in TI-CE regimen is well controlled by TDM. ${ }^{5}$ In children TDM for voriconazole is used to individualize the drug dosage. ${ }^{6}$ In MDR-TB, fluoroquinolone TDM is useful in predicting the exposure and to minimize the drug resistance. 7

TDM optimizes anti-TNF agents' therapy in treatment failure cases of inflammatory bowel disease. ${ }^{8}$ Pharmacogenetic knowledge is a requisite for effective employment of TDM while administering Flecainide. ${ }^{9}$ The role of TDM in the treatment of cardiovascular diseases is to increase the safety index of digoxin and few antiarrhythmic drugs. ${ }^{10}$

TDM is utilized for therapy with valproic acid, phenobarbital, carbamazepine and newer antiepileptic drugs such aseslicarbazepine acetate, zonisamide, felbamate, lacosamide, lamotrigine, gabapentin, levetiracetam, topiramate, pregabalin, perampanel, rufinamide, stiripentol, retigabine, tiagabine and vigabatrin. $^{11,12}$ TDM optimizes the efficacy, reduces the adverse drug reaction and cost of health care by individualizing the drug dosage of atypical antipsychotics and antidepressants. ${ }^{13,14}$

Nurses and lab technicians play a significant role in the process of TDM. Nurses play the role of phlebotomist and counselor. And since TDM is done in clinical laboratory, lab technicians must be aware of the rationale, utility and practice of the service. On taking their roles into account the current study is undertaken to assess the knowledge, attitude and practice of health care professionals towards TDM service. This study is aimed to benefit participants to know about their perceptions for TDM and to use them in the near future to improve the patient care.

\section{METHODS}

\section{Study area}

The study area was Father Muller Medical College, Mangalore, India.

\section{Study population}

Health care professionals (both male and female) working in Father Muller Medical College, Mangalore, India will be included in the study.

\section{Sample size}

Minimum of 384 participants were expected to participate according to the following calculation.

Estimate a proportion: $\frac{n \geq Z^{2} 1-\frac{\alpha}{2} \times p(1-p)}{d^{2}}$ alpha $(\alpha)=0.05$, estimated proportion $(p)=0.51$, estimated error $(d)=0.05$.

Convenient sampling technique. Pretested questionnairebased cross-sectional study will be done. Study was conducted from April to June 2019 for a period of 3 months.

\section{Inclusion criteria}

Inclusion criteria were health care professionals who were involved in the study are nurses, lab technicians.

\section{Exclusion criteria}

Exclusion criteria were health care professionals who were not willing to get involved in the study.

\section{Study procedure \\ Questionnaire validation}

Two sets of questionnaires were prepared, one set each for nurses and lab technicians. In the first set there was totally 19 questions, among them 9 were used to assess the knowledge, 4 were used to assess the attitude and 6 were used to assess the practice of TDM service. In the second set of questionnaires for lab technicians there were 10 questions, among which 6 were to assess the knowledge, 1to assess the attitude and 3 were used to assess the practice of TDM service. The credibility of the questionnaire was assessed by validation. Validation was done by doctors from psychiatry department, biochemistry department, community medicine department, and radiation oncology department.

\section{Approval}

The protocol was approved by the scientific committee, Father Muller research center.

\section{Enrollment and data collection}

Permission was sought from the administrator, Father Muller medical college hospital, and chief nursing officer Sir Janet D'Souza. Before distributing the questionnaire, study participants were completely explained about the importance of this study and by what ways it will benefit the society. A written informed consent was obtained from all the participants. 609 questionnaires were distributed to four batches of nursing staff on four days during their training programme. A time period of 15 minutes was allotted for them to answer the questionnaire. Later their queries regarding TDM were discussed and answered.

The second set of 20 questionnaires containing 10 questions each was distributed to 21 biochemistry lab technicians. They were informed about the study and they were given one day time to respond to the questions. Data 
collected was entered in an excel sheet for statistical analysis.

\section{Statistical analysis}

Frequency and percentage were used for categorical variables, mean and standard deviation were used for continuous variable and Pearson correlation was used to find relationship between variables.

\section{RESULTS}

Altogether the response rate percentage was $97.6 \%$. Response rate among nurses was $99.1 \%$. Response rate among lab technicians was $52.3 \%$.

\section{Demographic}

Demographic details of nursing staff and the lab technicians are represented in (Table 1 and 2) respectively. $49.6 \%$ of nursing staff and $36.6 \%$ of lab technicians fall under the age group 20 to 24 years. $68 \%$ of nursing staff and $36.3 \%$ of lab technicians falls under 0 to 3 years of work experience.

\section{Knowledge}

$7 \%$ of nurses had good knowledge on TDM, $60.9 \%$ of nurses had fair knowledge on TDM and $32.2 \%$ of nurses had poor knowledge on TDM. $18.2 \%$ of lab technicians had good knowledge on TDM. $81.8 \%$ of lab technicians had fair knowledge on TDM. Frequency and percentage of knowledge on TDM among nursing staff and lab technicians are represented in Table 3 and 4 respectively.
$76.5 \%$ of nursing staff are aware about the association between TDM and adverse drug reaction and $72.6 \%$ of nursing staff are aware about the constituent of the TDM team. All the lab technicians have knowledge on constituent of TDM team and samples used in TDM. $81.8 \%$ of lab technicians have knowledge on sample collection for TDM.

\section{Attitude}

$79.3 \%$ of nurses had favourable attitude towards TDM and $20.7 \%$ of nurses had unfavourable attitude towards TDM. Frequency and percentage of attitude on TDM among nursing staff are represented in (Table 5). 91.7\% nursing staff felt that Health care professionals should be trained on the fundamental principles of TDM during their course. 88.9\% nursing staff felt that TDM is must in all the hospitals.

All the lab technicians felt that TMD service should be mandatory in all the hospitals. Correlation between knowledge and attitude among nurses towards TDM is mentioned in the (Table 6). weak positive correlation is found between the knowledge and attitude of the nursing staff.

\section{Practice}

Among nurses, $58.5 \%$ are ready to use TDM unit if it is available in the institution, $13.3 \%$ are not willing to use TDM unit if it available in the institution. $22.6 \%$ are not very sure about using TDM unit. $22.4 \%$ are concerned about taking too many of blood samples for dose change while $20.4 \%$ say that TDM can increase the duration of stay in the hospital.

Table 1: Frequency distribution of study participants based on age.

\begin{tabular}{|lllll|}
\hline \multirow{2}{*}{ Age in years } & Nursing staff & & Lab technicians & Percentage \\
\hline $\mathbf{2 0 - 2 4}$ & Frequency & Percentage & Frequency & 36.6 \\
\hline $\mathbf{2 5 - 2 9}$ & 299 & 49.6 & 4 & 36.6 \\
\hline $\mathbf{3 0 - 3 4}$ & 164 & 27.2 & 4 & 9.09 \\
\hline $\mathbf{3 4 - 3 9}$ & 41 & 6.8 & 1 & 0 \\
\hline $\mathbf{4 0 - 4 4}$ & 13 & 2.2 & 0 & 0 \\
\hline $\mathbf{4 5}$ & 8 & 1.3 & 0 & 18.1 \\
\hline
\end{tabular}

Table 2: Frequency distribution of study participants based on years of experience.

\begin{tabular}{|lllll|}
\hline $\begin{array}{l}\text { Years of } \\
\text { experience }\end{array}$ & Nursing staff & & Lab technicians & Percentage \\
\hline $\mathbf{0 - 3}$ & 410 & Percentage & Frequency & 36.3 \\
\hline $\mathbf{4 - 6}$ & 62 & 68 & 4 & 27.2 \\
\hline $\mathbf{7 - 9}$ & 12 & 10.3 & 3 & 18.1 \\
\hline $\mathbf{1 0 - 1 2}$ & 10 & 2 & 2 & 0 \\
\hline $\mathbf{1 1 3}$ & 19 & 1.7 & 0 & 18.1 \\
\hline
\end{tabular}


Table 3: Frequency and percentage of knowledge items on TDM among nursing staff.

\begin{tabular}{|c|c|c|}
\hline Knowledge items & Response & $\begin{array}{l}\text { Nurses }(\mathbf{n}=603) \\
\text { N }(\%)\end{array}$ \\
\hline \multirow{3}{*}{ Knows that TDM is used to optimize drugs therapeutic effect } & Correct & $165(27.4)$ \\
\hline & Incorrect & $404(67)$ \\
\hline & Missing & $1(0.2)$ \\
\hline \multirow{3}{*}{$\begin{array}{l}\text { Awareness of association of TDM and incidents of adverse drug } \\
\text { reaction (ADR) }\end{array}$} & Correct & $461(76.5)$ \\
\hline & Incorrect & $142(23.5)$ \\
\hline & Missing & - \\
\hline \multirow{3}{*}{$\begin{array}{l}\text { Knows that measured drug concentration is low when patient is } \\
\text { fast metabolizer/not compliant }\end{array}$} & Correct & $177(29.4)$ \\
\hline & Incorrect & $425(70.5)$ \\
\hline & Missing & $1(0.2)$ \\
\hline \multirow{3}{*}{ Awareness that TDM reduces cost benefit ratio } & Correct & $278(46.1)$ \\
\hline & Incorrect & $325(53.9)$ \\
\hline & Missing & - \\
\hline \multirow{3}{*}{ Awareness about constituent of TDM team } & Correct & $438(72.6)$ \\
\hline & Incorrect & $198(32.8)$ \\
\hline & Missing & - \\
\hline \multirow{3}{*}{ Awareness about ideal time to get back TDM report } & Correct & $249(41.3)$ \\
\hline & Incorrect & $353(58.5)$ \\
\hline & Missing & $1(0.2)$ \\
\hline \multirow{3}{*}{ Familiar about the term narrow therapeutic index } & Correct & $203(33.7)$ \\
\hline & Incorrect & $400(66.3)$ \\
\hline & Missing & - \\
\hline \multirow{3}{*}{ Knowledge about types of sample used in TDM } & Correct & $215(35.7)$ \\
\hline & Incorrect & $388(64.3)$ \\
\hline & Missing & - \\
\hline \multirow{3}{*}{ Awareness on timing of sample collection } & Correct & $341(56.6)$ \\
\hline & Incorrect & $260(43.1)$ \\
\hline & Missing & - \\
\hline
\end{tabular}

Table 4: Frequency and percentage of knowledge items on TDM among lab technicians.

\begin{tabular}{|c|c|c|}
\hline Knowledge items & Response & $\begin{array}{l}\text { Lab technicians }(\mathbf{n}=\mathbf{1 1}) \\
\mathbf{N}(\%)\end{array}$ \\
\hline \multirow{3}{*}{ Familiar with the use of TDM } & Correct & $1(9.1)$ \\
\hline & Incorrect & $10(90.9)$ \\
\hline & Missing & - \\
\hline \multirow{3}{*}{$\begin{array}{l}\text { Measured drug concentration is low when patient is fast } \\
\text { metabolizer/ not compliant }\end{array}$} & Correct & $6(54.5)$ \\
\hline & Incorrect & $5(45.5)$ \\
\hline & Missing & - \\
\hline \multirow{3}{*}{ Awareness about constituent of TDM team } & Correct & $11(100)$ \\
\hline & Incorrect & - \\
\hline & Missing & - \\
\hline \multirow{3}{*}{ Awareness about ideal time to get back TDM report } & Correct & $6(54.5)$ \\
\hline & Incorrect & $5(45.5)$ \\
\hline & Missing & - \\
\hline \multirow{3}{*}{ Knowledge about types of sample used in TDM } & Correct & $11(100)$ \\
\hline & Incorrect & - \\
\hline & Missing & - \\
\hline \multirow{3}{*}{ Awareness on timing of sample collection } & Correct & $9(81.8)$ \\
\hline & Incorrect & $2(18.2)$ \\
\hline & Missing & - \\
\hline
\end{tabular}


Table 5: Frequency and percentage of attitude on TDM among nursing staff.

\begin{tabular}{|c|c|c|}
\hline Attitude items & Response & $\begin{array}{l}\text { Nurses }(n=603) \\
\text { N }(\%)\end{array}$ \\
\hline \multirow{5}{*}{$\begin{array}{l}\text { Health care professionals should be trained on the fundamental } \\
\text { principles of TDM during their course }\end{array}$} & Strongly agree & $307(50.9)$ \\
\hline & Agree & $246(40.8)$ \\
\hline & Uncertain & $31(5.1)$ \\
\hline & Disagree & $12(2)$ \\
\hline & Strongly disagree & $4(0.7)$ \\
\hline \multirow{5}{*}{ Reading article regarding TDM is useful } & Strongly agree & $224(37.1)$ \\
\hline & Agree & $315(52.2)$ \\
\hline & Uncertain & $40(6.6)$ \\
\hline & Disagree & $16(2.7)$ \\
\hline & Strongly disagree & $3(0.5)$ \\
\hline \multirow{5}{*}{ TDM is must in all the hospitals } & Strongly agree & $242(40.1)$ \\
\hline & Agree & $294(48.8)$ \\
\hline & Uncertain & $46(7.6)$ \\
\hline & Disagree & $14(2.3)$ \\
\hline & Strongly disagree & - \\
\hline \multirow{5}{*}{ Clinical outcome of patients is improved by TDM service } & Strongly agree & $195(32.3)$ \\
\hline & Agree & $307(50.9)$ \\
\hline & Uncertain & $72(11.9)$ \\
\hline & Disagree & $20(3.3)$ \\
\hline & $\begin{array}{l}\text { Strongly } \\
\text { disagree }\end{array}$ & $4(0.7)$ \\
\hline
\end{tabular}

Table 6: Correlation between knowledge and attitude among nurses towards TDM.

\begin{tabular}{|lllll|}
\hline Variable & Mean & Standard deviation & R value & P value \\
\hline Knowledge & 4.2620 & 1.53400 & $0.207^{* *}$ & $<0.001^{*}$ \\
\hline Attitude & 16.8988 & 2.57151 & \\
\hline
\end{tabular}

**Correlation is significant at the 0.01 level (2-tailed).

$23.4 \%$ are concerned that patients might not agree to the TDM process. $19.2 \%$ are concerned that TDM might increase the cost. The most common indication for TDM in their practice was narrow therapeutic index in $18.2 \%$ response, non-compliance in $15.4 \%$ response, prevention of ADRs in $53.4 \%$ response and poorly defined clinical end point in $5.1 \%$ of response. Drugs requested for TDM by the nursing staff in last one year is represented in (Figure 1). Phenytoin, sodium valproate, carbamazepine, methotrexate, lithium, clozapine, risperidone, tigecycline, vancomycin and gentamicin, digoxin, amiodarone were the drugs for which TDM was requested by $15.9 \%$ of the nurses in the last one year. About $8 \%$ of nursing staff have given erroneous response.

Percentage of nurses who felt the need for sending samples for TDM in the last one year is shown on (Table 7). $33.7 \%$ of nursing staff have not felt the need for sending samples for TDM.

Lab technicians have received and estimated drug levels for methotrexate and lithium during the last one year.
Approximately 21-40 samples were outsourced by them for TDM.

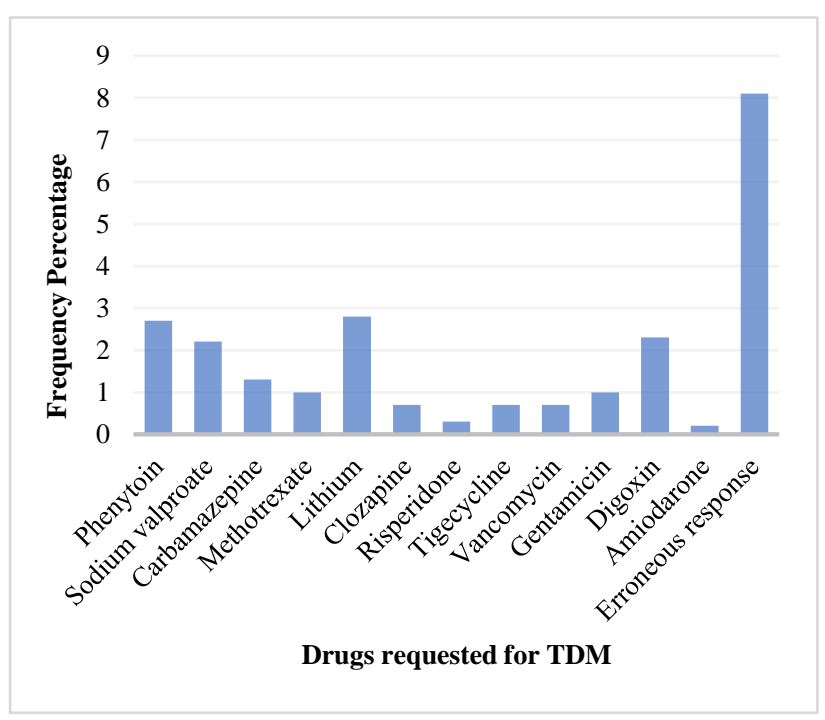

Figure 1: Drugs requested for TDM. 
Table 7: Percentage of nurses who felt the need for sending samples for TDM in the last one year.

\begin{tabular}{|c|c|}
\hline Nurses & Percentage \\
\hline $\begin{array}{l}\text { Who have not felt the need for } \\
\text { sending samples for TDM }\end{array}$ & 33.7 \\
\hline $\begin{array}{l}\text { Who felt the need for sending } 1-20 \\
\text { samples for TDM }\end{array}$ & 44.9 \\
\hline $\begin{array}{l}\text { Who felt the need for sending 21-40 } \\
\text { samples for TDM }\end{array}$ & 8 \\
\hline $\begin{array}{l}\text { Who felt the need for sending }>40 \\
\text { samples for TDM }\end{array}$ & 4.8 \\
\hline
\end{tabular}

Altogether the response rate percentage of study participants was $97.6 \%$. Response rate among nurses= $99.1 \%$ and response rate among lab technicians $=52.3 \%$.

\section{DISCUSSION}

\section{Percentage of response}

$614(97.5 \%)$ of health care professionals have responded to the questionnaires which reveals their positive attitude towards our research on TDM.

\section{Demographic details}

$49.6 \%$ of nursing staff and $36.6 \%$ of lab technicians fall under the age group 20 to 24 years and $27.2 \%$ of nursing staff and $36.6 \%$ of lab technicians are of age group 25 to 29 years. $68 \%$ of nursing staff and $36.3 \%$ of lab technicians falls under 0 to 3 years of work experience. Majority of them are in the early years of their profession.

\section{Knowledge}

Questions were framed to assess the knowledge on indications, pharmacokinetic basis, pharmacoeconomic impact, procedures, and type of sample collection in TDM. Only $7 \%$ of nurses was found to have a good knowledge on TDM. $32.2 \%$ had poor knowledge on TDM. Only $18.2 \%$ of lab technicians had good knowledge on TDM.

Among nurses $32.8 \%$ know why TDM is used. This is comparatively lesser than $98.43 \%$ in the TDM perception study in health-care workers in Nigeria $(98.43 \%) .{ }^{15}$ $76.5 \%$ know TDM reduces ADR and only $29.4 \%$ know it can be used to check non-compliance and identify fast metabolizers. This is because only few know about the fast metabolizers but many are aware of ADR reporting in pharmacovigilance program. $46.1 \%$ feel cost benefit ratio can be reduced by TDM but during practice $19 \%$ feel TDM increases the cost. A study done in Nebraska shows TDM can reduce hospital stay and markedly increase hospital savings in aminoglycoside induced nephrotoxicity patients. ${ }^{16} 72.6 \%$ knows that they are the part of TDM service. $41.5 \%$ are aware that TDM report must be back before next dosing of the concerned drug for dose adjustment. 33.7\% are aware of the term Narrow therapeutic index which is slightly higher when compared to a study done in UK to assess knowledge of nurses on pharmacology where only $26.1 \%$ got good scoring. ${ }^{17}$ $35.7 \%$ know what are the samples that should be collected and $56.6 \%$ knew that the timing of sample collection varies individually. This shows they are aware of the practical issues during sample collection.

Among lab technicians only $9.1 \%$ knew why TDM is used. $54.5 \%$ knew that it can be used to check noncompliance and to identify fast metabolizers and ideal time to send TDM report. All knows about members of TDM team and types of sample used in TDM. $81.8 \%$ know that the timing of sample collection varies individually. In the study done in Nigeria, all health care workers, viz doctors, nurses and lab technicians were involved in the study but data was calculated as a total and not individually. ${ }^{15}$ This drawback is corrected in this study though they are less in number. Lab technicians have adequate knowledge on procedure but inadequate knowledge on aims of TDM.

\section{Attitude}

Among nurses $79.3 \%$ had favourable attitude towards TDM. All lab technicians felt TDM is must in all the hospitals. A study done in England examined the current practice and perspective of psychiatrists regarding TDM on antipsychotics. The positive expectations and attitudes were in the upper hand when compared to the barriers, negative expectations and attitudes regarding TDM among doctors. ${ }^{18}$ Both of these studies show that the attitude towards TDM is very much positive among doctors, nursing staff and lab technicians. There was a weak positive correlation between the knowledge and attitude of the nursing staff. $92.7 \%$ of nurses felt they should be trained on fundamental principles of TDM during their course. $89.3 \%$ felt reading article on TDM is useful. $88.9 \%$ felt TDM is must in all the hospitals. $83.2 \%$ felt TDM improves outcome of patient.

\section{Practice}

TDM service in India are sorted of two types. Clinical pharmacology department offers TDM service in teaching hospitals and clinical biochemistry department offers drug estimations in private sector. ${ }^{19}$ Among nurses, $58.5 \%$ are ready to use TDM service if it is available in the institution. In England when study was done on $82.9 \%$ of doctors were ready to use TDM service based on availability. ${ }^{18}$ Though comparatively less, in our study nurses are ready to use the TDM service, but nurses were concerned about taking too many blood samples (22.4\%), increase in length of hospital stay $(20.4 \%)$, increase in cost of treatment $(19.2 \%)$ and patient consent $(23.4 \%)$. But in a TDM study done on antiretroviral treatment, these concerns were found to be resolved. It was found that TDM readily solved $52.1 \%$ of medication related 
complications and non- typical blood plasma levels during antiretroviral treatment. ${ }^{20}$ Hence, appropriate selection of drug candidate for TDM offers greater advantage against the cost.

Anticonvulsants like phenytoin, sodium valproate, carbamazepine; Anticancer drugs like methotrexate, Antipsychotics and antimanic drugs like lithium, clozapine, risperidone; antimicrobial agents; tigecycline, vancomycin and gentamicin; Cardiovascular drugs like digoxin, amiodarone were the drugs for which TDM was requested by $15.9 \%$ of the nurses in the last one year. In a survey conducted in two cancer centers in Jordan, drugs for which TDM was frequently requested were methotrexate, fluorouracil, tacrolimus, cyclosporine, carboplatin, busulfan and theophylline. ${ }^{21}$ Among these, TDM is requested only for Methotrexate in our study. $57.7 \%$ of nurses felt the need for sending samples for TDM while only $15.9 \%$ nurses actually have sent the samples for TDM in the last one year. This is because TDM service is available for only few drugs. TDM of methotrexate and lithium was done in our lab during the last one year. Other 21-40 drug samples were outsourced.

\section{CONCLUSION}

Though knowledge on indication and pharmacological basis of TDM is lacking among nurses and lab technicians, their knowledge on sample collection and sample type are good. They have a positive attitude towards TDM. As far as the practice is concerned, they have requested TDM for only 12 drugs, though TDM service is available for many more. TDM of only two drugs was done in the lab. For that reason, future training should focus on pharmacological basis, how to select appropriate drug candidate and indication for TDM service. TDM service of all drugs whose plasma level should be maintained within narrow range should be made available in all tertiary care institutions for the welfare of humanity.

\section{ACKNOWLEDGEMENTS}

I am extremely thankful to Mrs. Praseena for her statistical work in this research. I am extremely thankful to Dr. Safeekh AT HOD Psychiatry Department, Dr. Shivashankara AR Associate Professor Biochemistry Department, Dr. Sudhir Prabu H Associate Professor Community Medicine Department, and Dr. Sharaschandra Shankar Senior Resident Radiation Oncology Department Father Muller Medical College, Mangalore for validating the questionnaire.

Funding: No funding sources Conflict of interest: None declared

Ethical approval: The study was approved by the Father Muller Medical College Institutional Ethics Committee (FMMCIEC/ CCM/98/2019)

\section{REFERENCES}

1. Jang SH, Yan Z, Lazor JA. Therapeutic drug monitoring: A patient management tool for precision medicine. Clin Pharmacol Ther. 2016;99:148-50.

2. Hiemke C, Bergemann N, Clement HW, Conca A, Deckert J, Domschke K, et al. Consensus Guidelines for Therapeutic Drug Monitoring in Neuropsychopharmacology: Update 2017. Pharmacopsychiatry. 2018;51(1-2):9-62.

3. Lee JJ, Beumer JH, Chu E. Therapeutic drug monitoring of 5-fluorouracil. Cancer Chemother Pharmacol. 2016;78(3):447-64.

4. Verheijen RB, Yu H, Schellens JHM, Beijnen JH, Steeghs N, Huitema ADR. practical Recommendations for Therapeutic Drug Monitoring of Kinase Inhibitors in Oncology. Clin Pharmacol Ther. 2017;102(5):765-76.

5. Moeung S, Chevreau C, Broutin S, Guitton J, Lelièvre B, Ciccolini $\mathrm{J}$, et al. Therapeutic Drug Monitoring of Carboplatin in High-Dose Protocol (TI-CE) for Advanced Germ Cell Tumors: Pharmacokinetic Results of a Phase II Multicenter Study. Clin Cancer Res. 2017;23(23):7171-9.

6. Allegra S, Fatiguso G, Francia DS, Favata F, Pirro E, Carcieri C, et al. Therapeutic drug monitoring of voriconazole for treatment and prophylaxis of invasive fungal infection in children. $\mathrm{Br} \mathrm{J}$ Clin Pharmacol. 2018;84(1):197-203.

7. Falzon D, Jaramillo E, Gilpin C, Weyer K. Therapeutic drug monitoring to prevent acquired drug resistance of fluoroquinolones in the treatment of tuberculosis. Eur Respir J. 2017;49(4).

8. Mitrev N, Casteele VN, Seow CH, Andrews JM, Connor SJ, Moore GT, et al. consensus statements on therapeutic drug monitoring of anti-tumour necrosis factor therapy in inflammatory bowel diseases. Aliment Pharmacol Ther. 2017;46(11-12):1037-53.

9. Doki K. Use of Pharmacogenetic Information for Therapeutic Drug Monitoring of an Antiarrhythmic Drug. Yakugaku Zasshi. 2018;138(9):1145-50.

10. Aonuma K, Shiga T, Atarashi H, Doki K, Echizen H, Hagiwara N, et al. Guidelines for Therapeutic Drug Monitoring of Cardiovascular Drugs Clinical Use of Blood Drug Concentration Monitoring (JCS 2015) Digest Version. Circ J. 2017;81(4):581-612.

11. Serragui S, Zalagh F, Tanani DS, Ouammi L, Moussa LA, Badrane N, et al. Therapeutic drug monitoring of three antiepileptic drugs - back on twenty years of experience. Pan Afr Med J. 2016;25:10.

12. Jacob S, Nair AB. An Updated Overview on Therapeutic Drug Monitoring of Recent Antiepileptic Drugs. Drugs R D. 2016;16(4):303-16.

13. Urban AE, Cubala WJ. Therapeutic drug monitoring of atypical antipsychotics. Psychiatr Pol. 2017;51(6):1059-77.

14. Grundmann M, Kacirova I, Urinovska R. Therapeutic monitoring of psychoactive drugs - antidepressants: a review. Biomed Pap Med Fac Univ Palacky Olomouc Czech Repub. 2015;159(1):35-43. 
15. Aghahowa SE, Ekeocha LE, Uhumwangho MU. Therapeutic drug monitoring: Perception among health - care workers in a developing tertiary institution. Nig Hosp Prac. 2015;16:1-3.

16. Destache CJ. Use of therapeutic drug monitoring in pharmacoeconomics. Ther Drug Monit. 1993;15(6):608-10.

17. Ndosi ME, Newell R. Nurses knowledge of pharmacology behind drugs they commonly administer. J Clin Nurs. 2009;18(4):570-80.

18. Law S, Haddad PM, Chaudhry IB, Hussain N, Drake RJ, Flanagan RJ, et al. Antipsychotic therapeutic drug monitoring: Psychiatrists attitude and factors predicting likely future use. Ther $\mathrm{Adv}$ Psychopharmacol. 2015;5(4):214-23.

19. Gogtay NJ, Kshirsagar NA, Dalvi SS. Therapeutic drug monitoring in a developing country: an overview. Br J Clin Pharmacol. 2001;52(1):103-8.
20. Schoenenberger JA, Aragones AM, Cano SM, Puig T, Castello A, Arbones GX, et al. The advantages of therapeutic drug monitoring in patients receiving antiretroviral treatment and experiencing medicationrelated problems. Ther Drug Monit. 2013;35(1):71-7.

21. Sireen ARS. The current status and future prospects of therapeutic drug monitoring of chemotherapy in Jordan. JJPS. 2012;5:51-62.

Cite this article as: Rajaduraivelpandian PB, Udaykumar P. A cross sectional knowledge attitude practice study on therapeutic drug monitoring among health care professionals in a tertiary care hospital. Int J Basic Clin Pharmacol 2020;9:879-86. 